\title{
Performance of Composite Filters Assembled from Multiple Layers of Basic Filtration Media
}

\author{
Peng Wang ${ }^{1}$, Zhen Liu ${ }^{1,2}$, Da-Ren Chen ${ }^{1 *}$ \\ ${ }^{1}$ Particle Laboratory, Department of Mechanical and Nuclear Engineering, Virginia Commonwealth University, \\ Richmond, VA 23284, USA \\ ${ }^{2}$ Beijing Key Laboratory of Process Fluid Filtration and Separation, College of Mechanical and Transportation \\ Engineering, China University of Petroleum, Beijing 102249, China
}

\begin{abstract}
There is a severe shortage of face masks and N95 respirators due to the current COVID-19 pandemic, particularly in countries that were not well prepared in advance. In order to help ease the supply demands of these resources, a strategy of using multiple layers of basic filtration media to construct a composite filter that can match the particle collection efficiency offered by a N95 filtering facepiece respirator (FFR) is proposed. In this study, the filtration performances of four face masks and one N95 respirator using the same test protocol (as a reference) were first compared. Composite filter samples composed of multiple layers of basic face mask and MERV13 furnace media were then constructed and the filter performance of the composite filters was investigated. As expected, the minimum particle collection efficiency of the N95 respirator media sample was higher than $95 \%$ and the efficiency of the samples from the four tested face masks varied from $71.8 \%$ to $83.6 \%$. The Figure of Merit (FOM) values of the face mask samples were generally half that of the N95 media sample. It was found that a N95-comparable collection efficiency can be achieved by combining two/three layers of face mask media but at the expense of a higher media pressure drop. Additionally, the composite filter samples made up of three/five layers of MERV13 furnace media could approach the FOM offered by the N95 media without the increased pressure drop. It was also found that the measured collection efficiency of multiple-layered filter media was not equal to the calculated in the test particle size range. Further studies are required to identify the reason(s).
\end{abstract}

Keywords: COVID-19; N95 respirator; Face mask; Collection efficiency; Figure of merit.

\section{INTRODUCTION}

COVID-19, the disease caused by Severe Acute Respiratory Syndrome CoronaVirus 2 (SARS-CoV-2), has been spreading globally since the first case reported in December 2019. This new coronavirus has a higher mortality rate than the seasonal influenza and is more infectious than either SARS or MERS (Middle East Respiratory Syndrome), the other known respiratory diseases caused by coronaviruses (Liu et al., 2020; Prompetchara et al., 2020; Wilder-Smith et al., 2020). Respiratory viruses can be transmitted via the droplets and droplet-nuclei produced by infected individuals from coughing, sneezing, speaking, and even breathing (Yang et al., 2007; Stelzer-Braid et al., 2009; Kutter et al., 2018). The World Health Organization (WHO) classifies respiratory aerosols with diameters larger than $5 \mu \mathrm{m}$ as droplets and those with diameters less than $5 \mu \mathrm{m}$ as droplet-nuclei (WHO, 2014).

\footnotetext{
* Corresponding author.

E-mail address: dchen3@vcu.edu
}

Due to gravitational forces, large droplets settle quickly on the mucosa of close contacts or environmental surfaces and can rarely travel more than $1-2 \mathrm{~m}$ from their origination sources. For small aerosols, e.g., droplet nuclei, they can be suspended in the air for a prolonged period of time and travel long distances from their sources (Xie et al., 2007; Gralton et al., 2011). Face masks have been used to prevent the transmission of respiratory aerosols (MacIntyre et al., 2009; Cowling et al., 2010). Among the various face masks designed for commonplace use, medical masks (also known as surgical/procedure masks) and filtering facepiece respirators (FFRs) are the most commonly used. Medical masks are designed to protect a sterile medical field from contamination by particles exhaled by patients and health workers, or to reduce the exposure of healthcare workers to blood and other bodily fluids during medical procedures. By their original design, medical masks are not appropriate for protecting wearers from small respiratory particles due to their inadequate filtering and fitting attributes. In contrast, FFRs are designed to cover the human nose and mouth tightly in order to protect wearers from airborne particles, such as biological materials (e.g., mold, Bacillus anthracis, 
mycobacterium tuberculosis), SARS viruses, Avian Flu, Ebola Virus, etc. and particulate matters (PM). FFRs thus provide much better protection than face masks.

The US National Institute for Occupational Safety and Health (NIOSH) certifies FFRs under regulation 42 CFR Part 84. Based on their resistance and media degradation, particulate respirators are classified into the $\mathrm{N}$ (non-resistant), $\mathrm{R}$ (resistant), and $\mathrm{P}$ (proof) series. PPRs with the minimum particle filtration efficiency of $95 \%, 99 \%$ and $99.97 \%$ are rated as 95, 99 and 100, respectively. To measure the filtration efficiency, the FFRs in the $\mathrm{N}$ series are challenged by continuously flowing neutralized polydisperse $\mathrm{NaCl}$ solid particles with a count median diameter (CMD) of $0.075 \pm$ $0.020 \mu \mathrm{m}$ and a geometry standard deviation (GSD) of $>1.86$ at a flow rate of $85 \pm 4 \mathrm{~L} \mathrm{~min}^{-1}$ through the respirators. Neutralized polydisperse dioctyl phthalate (DOP) liquid particles with a CMD of $0.185 \pm 0.020 \mu \mathrm{m}$ and a GSD of $>1.6$ are used for PPRs in the R and P series. An entire FFR with the effective filtration area of $135 \mathrm{~cm}^{2}$ is tested under the $85 \mathrm{~L} \mathrm{~min}^{-1}$ flow rate, resulting in a face velocity of $\sim 10.5$ $\mathrm{cm} \mathrm{s}^{-1}$. The mass concentration of particles upstream and downstream of a test FFR are measured by a light-scattering photometer, under the condition that the upstream particle concentration should not exceed $200 \mathrm{mg} \mathrm{m}^{-3}$. Table S1 lists the test standards for the filtration efficiency of FFRs in various countries/regions for reference.

Surgical masks are cleared by the Food and Drug Administration (FDA) in the US. The tested parameters for surgical masks include fluid resistance, particulate filtration efficiency (PFE), bacteria filtration efficiency (BFE), differential pressure, and flammability. For the PFE, as shown in Table S2, neutralized latex spheres in the size range of $0.1-5 \mu \mathrm{m}$ and at a face velocity of $0.5-25 \mathrm{~cm}^{-1} \mathrm{~s}$ are flowed through a circular sample of surgical mask media with a diameter of $50-150 \mathrm{~mm}$, according to the ASTM 2299 standard. Optical particle counters are used to measure the particle number concentration both upstream and downstream of the filter sample under the condition that the upstream particle number concentration should be less than $10^{2}$ particles $\mathrm{cm}^{-13}$. In contrast to the ASTM F2299 standard, un-neutralized polystyrene latex particles of $0.1 \mu \mathrm{m}$ in diameter are recommended in the FDA guidelines. The BFE of surgical masks is tested using un-neutralized staphylococcus aureus bacteria aerosols with a mean particle size (MPS) of $3.0 \pm 0.3 \mu \mathrm{m}$ at a flow rate of $28.3 \mathrm{~L} \mathrm{~min}^{-1}$ against a whole surgical mask according to the ASTM F2101-19 standards and FDA guidelines. A six-stage viable particle cascade impactor is recommended for collecting the bacterial aerosols. The bacterial aerosol delivery rate must be maintained at 1,700-3,000 viable particles per test. The testing methods in other countries and regions are also given in Table S2 for reference. No standard has been established in Europe or Japan for the PFE testing of surgical masks. In comparison, FFRs and surgical masks are divided into various levels according to their minimum filtration efficiency. Table S3 summarizes the efficiency level of face masks in US, China, Europe and Japan. Note that it is known that the particle collection efficiency of filter media depends on the size, shape, and charge status of particles; the electrical charge status of the filter media; and face velocity. As shown in Tables S1 and S2, the testing of surgical masks and FFRs was done under different conditions. Therefore, one cannot directly compare the filtration efficiencies of surgical masks and FFRs simply based on the data obtained by the testing standards presented.

The filtration performance of FFRs has been widely investigated (e.g., Brosseau et al., 1997; Balazy et al., 2006a, b; Eninger et al., 2008; Rengasamy et al., 2008; Eshbaugh et al., 2009; Rengasamy et al., 2009; Cho et al., 2010; He et al., 2013; Zuo et al., 2013). For example, Balazy et al. (2006b) evaluated the filtration performance of N95 FFRs using $\mathrm{NaCl}$ particles ranging from 10 to $600 \mathrm{~nm}$ in diameter. They found that the most penetrating particle sizes (MPPS) of N95 FFRs were in the size range of 30-70 nm. The shift of the MPPS towards nanometer-sized particles was found to be due primarily to the additional electrostatic collection mechanism included in electret filter media which are commonly used in N95 FFRs. Eninger et al. (2008) examined the performance of three FFRs, two N99 FFRs and one N95, with $\mathrm{NaCl}$ particles in the sub-micrometer sizes and three virus aerosols, using flow rates of 30,85 , and $150 \mathrm{~L} \mathrm{~min}^{-1}$. They confirmed that the MPPS was less than $0.1 \mu \mathrm{m}$ and that an increase in flow rate can significantly increase the particle penetration. Rengasamy et al. (2008) tested five N95 and two P100 FFRs with monodisperse silver particles of 4, 8, 12, 16, 20 and $30 \mathrm{~nm}$ at a flow rate of $85 \mathrm{~L} \mathrm{~min}^{-1}$. They concluded the NIOSH-approved FFRs can provide the expected levels of filtration efficiency against nanoparticles. Huang et al. (2013) examined the effects of face velocity, fiber diameter, packing density, filter thickness, and fiber charge density on the filtration characteristics of particulate respirators. They found that, for electret filter media, the MPPS increased with the increase of fiber diameter and face velocity, and decreased with the increase of packing density, thickness, fiber charge density, and filter thickness.

Others have investigated the performance of surgical masks (Willeke et al., 1996; Balazy et al., 2006a; Lee et al., 2008; Oberg and Brosseau, 2008). Willeke et al. (1996) measured the penetration of bacteria with different shapes and aerodynamic sizes through surgical masks under various flow rates and compared them with the penetration of oil particles of the same aerodynamic sizes. It was found that the penetration of surgical masks decreased with an increased aspect ratio of the bacterial dimensions, and that the penetration of spherical particles is always higher than that of bacteria particles. Balazy et al. (2006a) measured the filtration efficiency of two surgical masks with the MS2 virus in the particle size range of $10-80 \mathrm{~nm}$ under the inhalation flow rate of $85 \mathrm{~L} \mathrm{~min}^{-1}$. They observed that some surgical masks may provide very low protection against airborne viruses in this size range. Lee et al. (2008) did human test subject evaluations for four FFRs and three surgical masks using $\mathrm{NaCl}$ particles in the $0.04-1.3 \mu \mathrm{m}$ size range. They showed that the protection factor (i.e., the ratio of particle concentration outside the respirator to that of inside the respirator, which is equal to the reciprocal of the particle penetration) of surgical masks was 8-12 times less than that of FFRs on average. Oberg and Brosseau (2008) measured the penetration 
of 9 surgical masks using monodisperse latex spheres of $0.895,2.0$ and $3.1 \mu \mathrm{m}$ diameters at the flow rate $6 \mathrm{~L} \mathrm{~min}^{-1}$ and polydisperse $\mathrm{NaCl}$ particles with a CMD of $0.075 \mu \mathrm{m}$ at the flow rate of $84 \mathrm{~L} \mathrm{~min}^{-1}$. They concluded that surgical masks exhibited a wide range of $0 \%-84 \%$ particle penetrations for latex particles of three selected sizes and a similar range of $4 \%-90 \%$ for the penetration of $\mathrm{NaCl}$ particles.

Though the filtration performance for large bacteria has been reported, limited research has been done on the filtration of surgical masks for ultrafine particles in the virus size range. Due to difference testing standards, it is difficult to make direct comparisons on the filtration performance (i.e., particle collection efficiency) of FFRs and surgical masks. Moreover, the wide-spread urgent demand of N95 FFRs during the current COVID-19 pandemic has resulted in a severe shortage of N95 FFRs in various countries/regions, especially in the ones ill-supplied before the pandemic. The strategy of using multiple layers of basic filter media such as those used in face masks and furnace filter media to construct composite filter media with particle collection efficiencies matching that offered by N95 FFRs is proposed as an alternative to N95 FFR media. The pros and cons of this strategy have not been scientifically investigated to the authors' knowledge (although the general rule of thumb is known). The objectives of this study are thus to (1) directly compare the filtration performance of FFRs and surgical masks under the same testing protocol using $\mathrm{NaCl}$ particles to represent virus particles (Eninger et al., 2008; Davidson et al., 2013); (2) study the filtration performance of composite filters, assembled by loosely layering multiple layers of basic filtration media that are readily available in the market; and (3) examine the additivity of the filtration performance of the above composite filters.

\section{EXPERIMENTAL PROTOCOL}

\section{Experimental Setup}

Fig. 1 shows a schematic diagram of the experimental setup used in this study. A custom-made Collison atomizer with $\mathrm{NaCl}$ solution $(2 \% \mathrm{NaCl}$ by volume in DI water) was used to generate polydisperse $\mathrm{NaCl}$ droplets. The produced $\mathrm{NaCl}$ droplets were passed through the diffusion dryer with silica gel as the desiccant to obtain solid $\mathrm{NaCl}$ particles. A bypass line with a HEPA filter and a needle valve as the aerosol flow exhaust line was included in the setup in order to vary the flow rate of the aerosol stream entering the Differential Mobility Analyzer (DMA, TSI 3081). Before the aerosol stream enters the DMA, it is directed through a $\mathrm{Kr}^{85}$ neutralizer which is included in the DMA platform TSI 3080 to achieve a stationary charge distribution on the $\mathrm{NaCl}$ particles. The DMA was operated at aerosol and sheath flow rates of 0.5 and $3 \mathrm{~L} \mathrm{~min}^{-1}$, respectively, for the classification of particles based on their electrical mobilities. By fixing the DC voltage on the DMA, particles having the electrical mobilities in a narrow range were classified and passed through a $\mathrm{Po}^{210}$ neutralizer to reduce the particle charge status to the stationary state. The DMA-classified particles were then used as test particles. By varying the DMA voltage, particles with different electrical mobilities could be selected. During the filter testing, the upstream concentration of

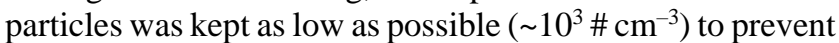
the test filter sample from the particle loading. It is the basis for testing the filter samples using particles in a narrow size distribution instead of ones in a wide size distribution.

A test filter sample was placed in a $47 \mathrm{~mm}$ inline filter holder with an effective filtration area of $10.15 \mathrm{~cm}^{2}$. A make-up air line with a HEPA filter capsule was included

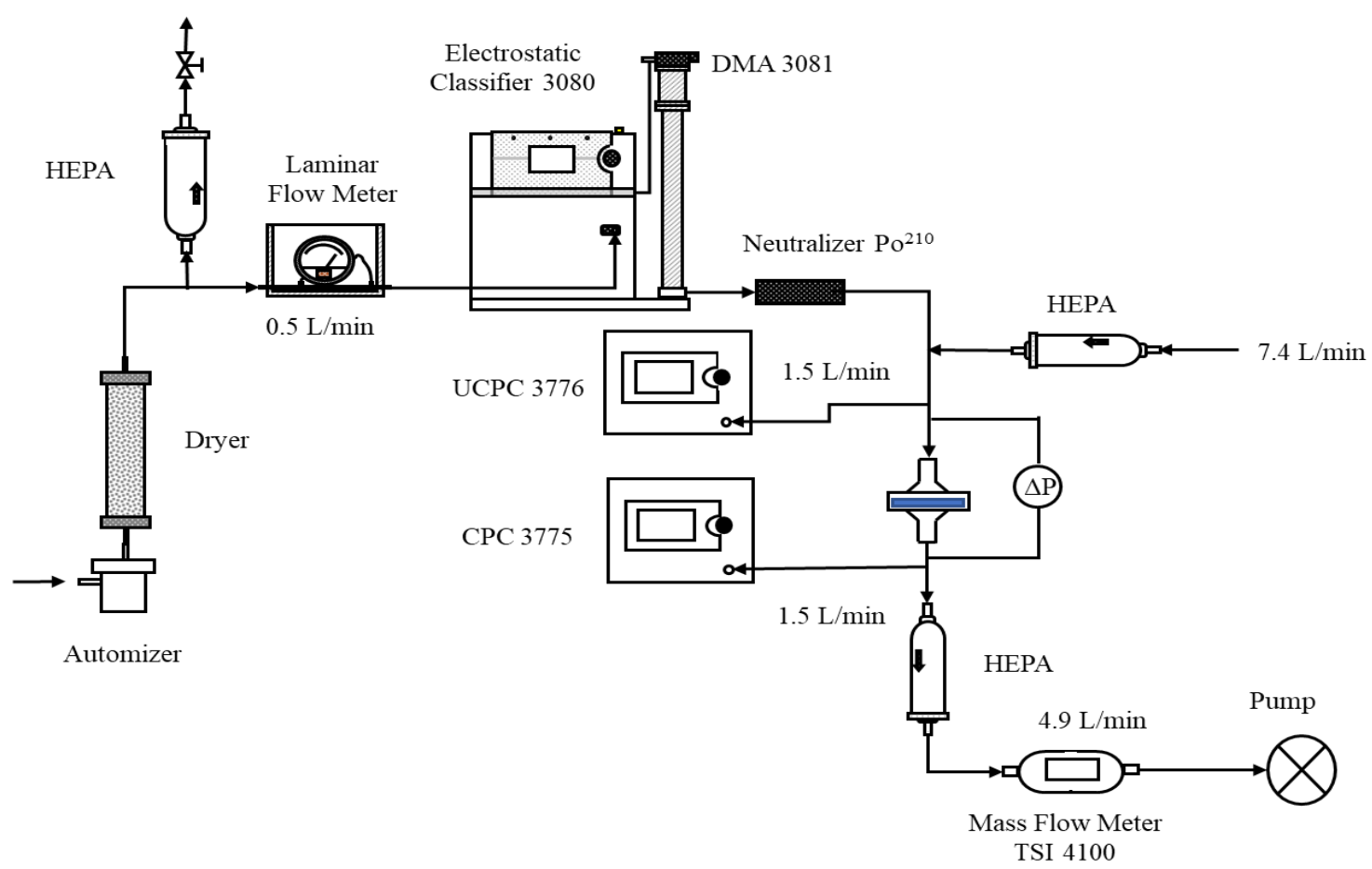

Fig. 1. Schematic diagram of the experimental setup used in this study. 
before the filter holder to passively introduce clean air from the ambient environment into the setup. The total flow rate through the filter holder was set at $6.4 \mathrm{~L} \mathrm{~min}^{-1}$, which is equivalent to a flow rate of $85 \mathrm{~L} \mathrm{~min}^{-1}$ for a whole FFR with a filtration area of $\sim 135 \mathrm{~cm}^{2}$ providing a face velocity of $\sim 10.5 \mathrm{~cm} \mathrm{~s}^{-1}$. An Ultrafine Condensation Particle Counter (UCPC, TSI 3776) and a Condensation Particle Counter (CPC, TSI 3775), operated at the $1.5 \mathrm{~L} \mathrm{~min}^{-1}$ high flow mode, were used to measure the particle concentrations upstream and downstream of the filter holder, respectively. A HEPA filter capsule was installed downstream of the filter holder to collect particles penetrating through the test filter sample. A mass flow meter (TSI 4000), a needle valve, and a vacuum pump were installed after the HEPA capsule to pull the 4.9 $\mathrm{L} \mathrm{min}^{-1}$ air flow through the line. The required test flow rate of $6.4 \mathrm{~L} \mathrm{~min}^{-1}$ was obtained by adding the $\mathrm{CPC}$ sampling flow rate $\left(1.5 \mathrm{~L} \mathrm{~min}^{-1}\right)$ and the $4.9 \mathrm{~L} \mathrm{~min}^{-1}$ air flow rate. A differential pressure transducer (OMEGA PX655-01DL) was used to measure the pressure drop across the test filter sample. Prior to the efficiency measurement, an experiment to calibrate both $\mathrm{CPC}$ readings by feeding DMA-classified particles into the two CPCs (with no filter sample in the filter holder) was conducted. The background pressure drop across the empty filter holder was also measured for data analysis.

\section{Test Filter Samples and Data Analysis}

Filter samples punched out from one N95 FFRs and four face masks (one surgical mask, one procedure mask, one face mask with coconut shell activated carbon, and one singleuse medical mask) were tested in this part of the study. In addition, furnace filter media with the minimum reported efficiency value of 13 (MERV 13) was also included as one of the basic filtration media in the alternative FFR filter media part of this study. Table 1 shows the label designation and rated particle filtration efficiency of the test filter media provided by the manufacturers. Composite filter media assembled from multiple layers of mask/furnace filter media listed in Table 1 were also tested. The measured pressure drops across all the test filter samples at the face velocity of $10.5 \mathrm{~cm} \mathrm{~s}^{-1}$ are given in Table 2 .

For the particle collection efficiency measurements in this study, test particles with the DMA-classified diameters of $20,30,50,75,100,150,200,300,400,600$, and $800 \mathrm{~nm}$ were used. The collection efficiency of each filter sample at a given particle size was calculated as:

$$
E=\left(1-\frac{C_{\text {down }}}{C_{u p}}\right) \times 100 \%
$$

where $\mathrm{E}$ is the particle collection efficiency of a test filter sample and $\mathrm{C}_{\text {down }}$ and $\mathrm{C}_{\text {up }}$ is the average particle number concentrations downstream and upstream of a test filter sample, respectively. The collection efficiency based on particle number concentration was selected for use in this study because this testing method is more rigorous than that of the method based on mass concentration for evaluating the worst-scenario performance of a filter sample (Rengasamy et al., 2011). At least three filter samples randomly selected from each face mask and FFR were tested in each case and the averages of the measured data were reported. The pressure drop of each filter sample was also measured at the beginning and ending of the filtration testing to ensure no particle loading effect occurred during the testing.

The Figure of Merit (FOM) for a filter sample of a specific size can be calculated as:

$f=\frac{-\ln (1-E)}{\Delta P}$

Table 1. The label designation of studied filter media samples from four face masks and one N95 FFR media and their rated particle filtration efficiency (given by the manufacturer).

\begin{tabular}{lll}
\hline $\begin{array}{l}\text { Sample } \\
\text { Label }\end{array}$ & Type of Masks & $\begin{array}{l}\text { Rated Filtration efficiency (by the } \\
\text { manufacturers) }\end{array}$ \\
\hline A & N95 particulate FFRs & $\geq 95 \%$, NIOSH certified \\
B & Tie-on face surgical mask, & NA \\
C & Ear-loop procedure mask & ASTM Level 1 (BFE $\geq 95 \%$, PFE $\geq 95 \%)$ \\
D & Ear-loop face mask (with cocoanut shell activated carbon) & $\geq 98 \%$ for particles larger than $3.1 \mu \mathrm{m}$ \\
E & Ear-loop medical mask & BFE $\geq 95 \%$ \\
F & Furnace filter media & MERV 13 \\
\hline
\end{tabular}

Table 2. Summary of the measured pressure drop of all the test filter samples (with basic media and composite media) at the face velocity of $10.5 \mathrm{~cm} \mathrm{~s}^{-1}$.

\begin{tabular}{llll}
\hline Media Sample & Pressure drop $(\mathrm{Pa})$ & Composite Samples & Pressure drop $(\mathrm{Pa})$ \\
\hline A & $81.1 \pm 4.9$ & B_double layers & $95.2 \pm 8.4$ \\
B & $45.1 \pm 7.7$ & B_triple layers & $158.0 \pm 15.4$ \\
C & $64.3 \pm 5.1$ & C_double layers & $127.7 \pm 11.9$ \\
D & $67.7 \pm 6.2$ & D_double layers & $120.2 \pm 10.2$ \\
E & $59.6 \pm 4.6$ & E_double layers & $128.7 \pm 3.9$ \\
F & $9.3 \pm 1.2$ & F_triple layers & $30.0 \pm 2.0$ \\
& & F_five layers & $50.6 \pm 0.7$ \\
\hline
\end{tabular}


where $\mathrm{f}$ is the figure of merit (units of $\mathrm{Pa}^{-1}$ ) and $\Delta \mathrm{P}$ is the pressure drop in units of $\mathrm{Pa}$. Note that the FOM is not dimensionless and depends on the unit selected for the pressure drop.

\section{RESULTS AND DISCUSSION}

\section{Comparison of Filtration Efficiency of Respirator and Mask Filter Samples}

Fig. 2 shows the size-fractionated filtration efficiency of filter samples obtained from the FFR and the four face masks as the function of the particle size under a face velocity of $10.5 \mathrm{~cm} \mathrm{~s}^{-1}$. For all the test sizes, the collection efficiency of the electret N95 FFR sample was much higher than that of the face mask samples. Its minimum particle efficiency was more than $95 \%$ at the most penetration particle size (MPPS) of $\sim 50 \mathrm{~nm}$. For a FFR sample with electret media, the particle diffusion dominates in the media for collecting particles of sizes less than $50 \mathrm{~nm}$, while both interception and electrostatic mechanisms play major roles in the media to remove particles of sizes larger than $50 \mathrm{~nm}$ (Romay et al., 1998). The MMPS was found to be the particle size in which the transition from diffusion-dominated collection to interception and electrostatic force-dominated collection occurs. The particle collection efficiency of the face mask samples at the MMPS varied from $71.8 \%-83.6 \%$. Filter sample B, taken from a surgical mask, having the lowest particle collection was expected due to its usual application in dental service. The MPPS of all the face mask samples was measured to be $\sim 50 \mathrm{~nm}$, which is close to that of the electret FFR filter sample. This observation implies that all the face masks selected in this study were likely made of different grades of electret filter media. Fig. 3 shows the FOM for each filter sample as a function of the particle size. The N95 FFR sample has a higher FOM value

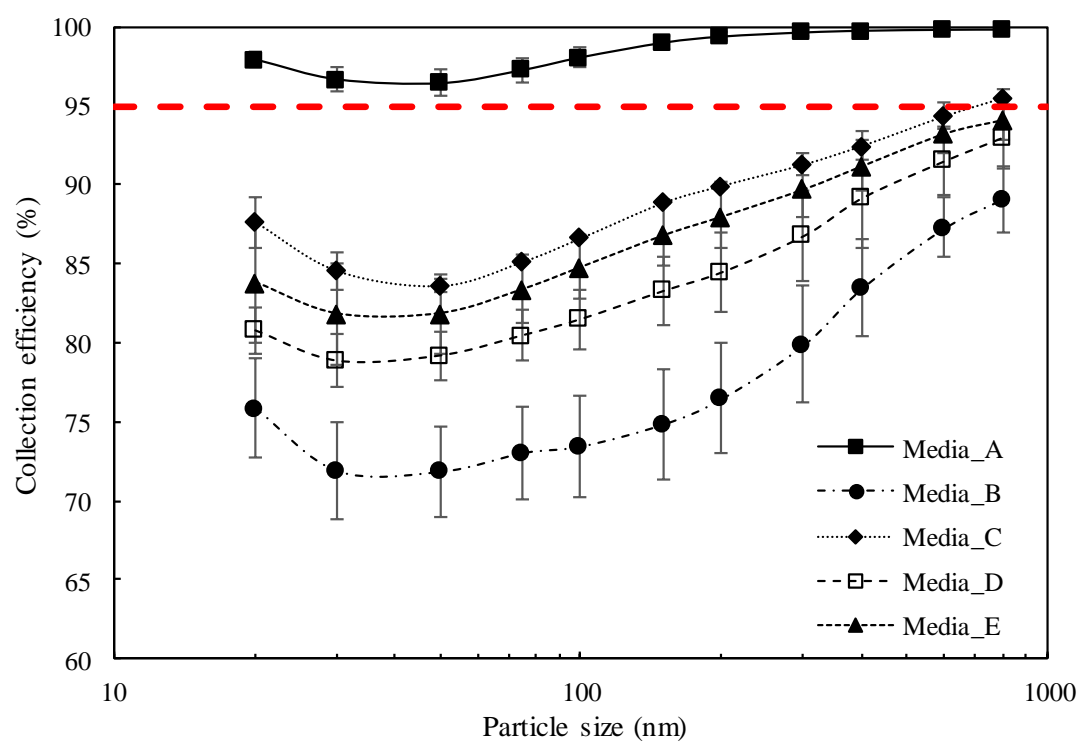

Fig. 2. The measured size-fractionated efficiency of the FFR and face mask samples at the face velocity of $10.5 \mathrm{~cm} \mathrm{~s}^{-1}$.

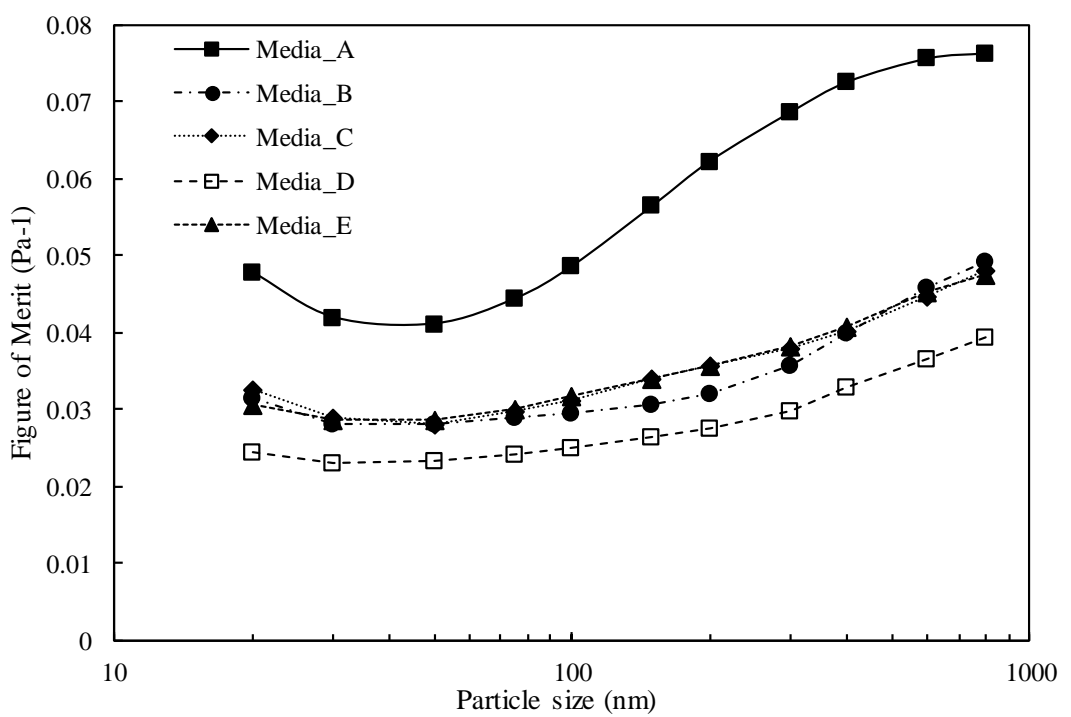

Fig. 3. The size-fractionated figure of merit (FOM) of the FFR and face mask samples at the face velocity of $10.5 \mathrm{~cm} \mathrm{~s}^{-1}$. 
compared to all the face mask samples, particularly for large particles. Except for the low FOM of the filter sample D, the filter samples from the other three face masks had very close FOM curves (as a function of the particle size).

\section{Composite Media Matching the Collection Efficiency of N95 FFRs}

One simple way of constructing alternative media for N95 FFRs is by combining multiple layers of basic filtration media. Face masks and furnace filter panels are readily available on the market and were thus selected as basic filtration media in this part of the study. Fig. 4 shows the particle collection efficiency of the multi-layered composite filter samples at the selected particle sizes under the face velocity of $10.5 \mathrm{~cm} \mathrm{~s}^{-1}$. It is shown that for all the test sizes, the particle collection efficiencies of double- and triple- layered mask filter samples are significantly higher than that of their basic filtration media counterparts (shown in Fig. 2). Triple-layered B media and double-layered C, D, E media samples have collection efficiencies of more than $93 \%$ for particles larger than $100 \mathrm{~nm}$. Fig. 4 also shows that the MMPS remained unchanged by doubling/tripling the face mask media. Since the typical particle size range of SARS-CoV-2 is between 60 to $140 \mathrm{~nm}$, with a mean diameter of $100 \mathrm{~nm}$ measured by electron micrographs (Zhu et al., 2020), double/triple-layered face masks can offer comparable protection from SARS-CoV-2 to that of a N95 respirator from the viewpoint of particle collection efficiency.

The particle collection efficiency of three- and five-layer MER 13 furnace filter media (i.e., Media F) test samples as a function of the particle size is also included in Fig. 4. Furnace filter media was selected as another basic filtration media because it is widely available in the hardware stores during the COVID-19 pandemic and low in cost. More importantly, it is electret filter media of low grades. As shown in Fig. 4, composite filter samples with triple layers of the selected furnace filter media have collection efficiencies higher than $95 \%$ for particles larger than $100 \mathrm{~nm}$. The filter samples' efficiencies were, however, less than $95 \%$ for particles smaller than $100 \mathrm{~nm}$, because of the wide opening in low grade electret media compared to that of N95 FFR media. For particles larger than $100 \mathrm{~nm}$, electrostatic forces dominate in particle collection within electret media, resulting in a high particle collection efficiency. For particles less than $100 \mathrm{~nm}$ in diameter, the particle collection of the media by electrostatic forces is weakened due to the small particle sizes. Collection by particle diffusion in the furnace filter media is also not very effective due to the wide-open microstructure of the media compared to the N95 FFR media. For the sample with five layers of basic furnace filter media, its collection efficiency increased significantly for particles in the sizes less than $100 \mathrm{~nm}$ because of the increased particle residence time in the sample. As a result, the minimum particle collection efficiency of five-layered furnace media composite sample was $94.6 \%$ compared to $84.9 \%$ for the three-layers media sample. Notice that the MPPS of the five-layered furnace media composite sample was at $\sim 30 \mathrm{~nm}$, smaller than that of the N95 respirator and the face masks.

The trade-off in using composite filters constructed from multiple layers of basic filtration media to achieve the N95 FFR media efficiency is typically assumed to be the increased filter pressure drop (compared to the N95 FFRs). The pressure drops for a given multi-layered composite filter sample was assumed to be the sum of the pressure drops of the individual media layers. Fig. 5 shows the FOM of the multi-layered mask and furnace media composite samples as a function of the particle size. The FOM of the N95 FFR sample is also included in Fig. 5 as a reference. A negligible difference in the FOM curves was observed among all the multi-layered face mask samples. Additionally, the FOM values of face mask composite samples were generally lower than that of the N95 FFP sample ( $\sim$ half the FOM value of the N95 FFR sample). This data proves that the N95-comparable efficiency of double/triple- layered mask composite samples is indeed

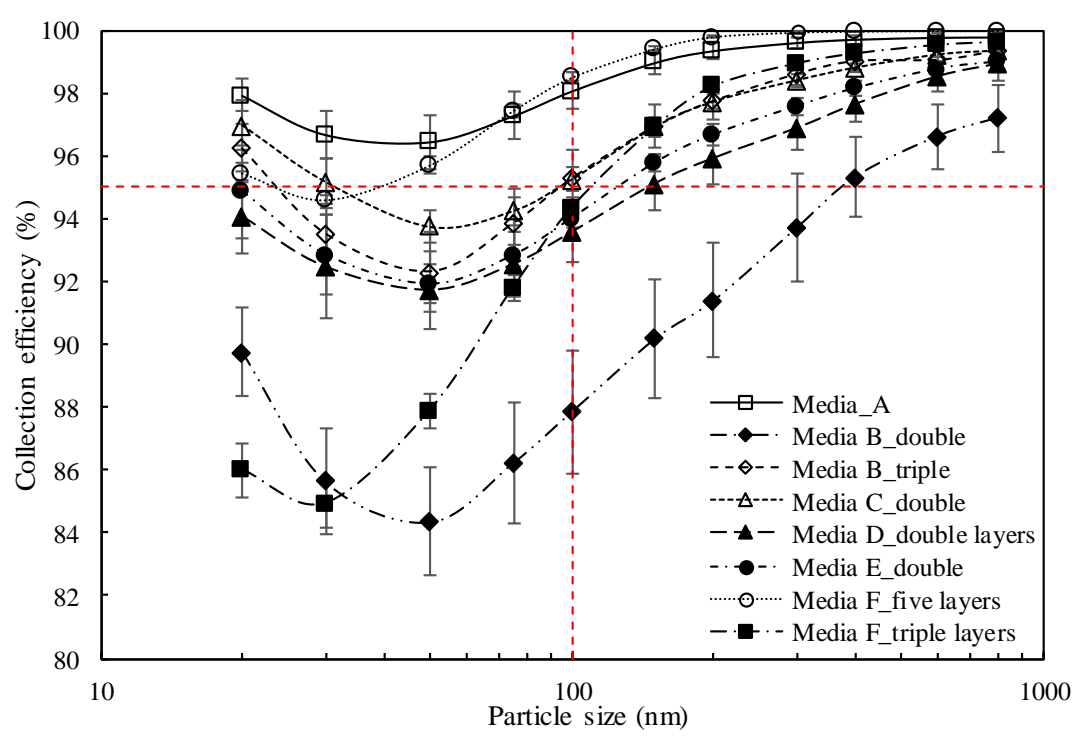

Fig. 4. The size-fractionated collection efficiency of the composite filter samples composed of multiple layers of basic face mask and furnace media (loosely layered) at the face velocity of $10.5 \mathrm{~cm} \mathrm{~s}^{-1}$. 


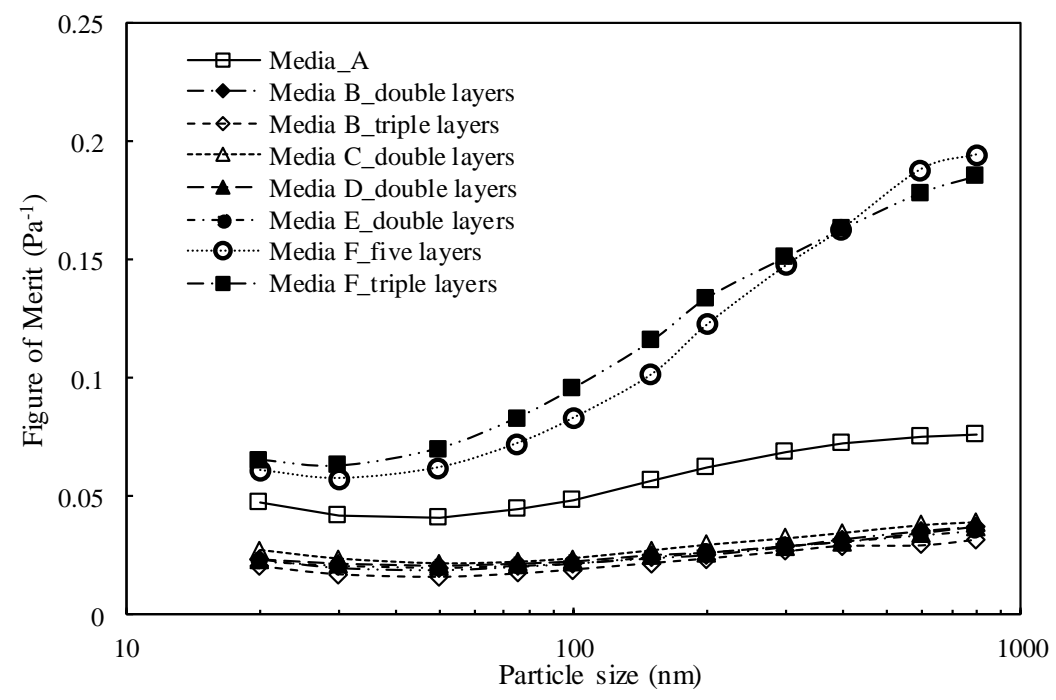

Fig. 5. The comparison on the FOM of the N95 FFR and composite filter samples at the face velocity of $10.5 \mathrm{~cm} \mathrm{~s}^{-1}$.

achieved at the expense of an increased pressure drop for most cases using face mask samples. However, in the cases of the composite filter samples made of multiple layers of furnace filter media, their FOM values were higher than that of the N95 FFR sample, particularly for particles larger than $100 \mathrm{~nm}$. Based on the FOM values given above, composite filters made of multiple furnace filter media layers would be preferred as an alternative for a N95 FFR. Notice that although the FOM values for the composite samples made of multiple layers of face mask filter media were less than that of the N95 FFR sample, the pressure drops for all the tested composite samples remained within the allowable pressure drop range (i.e., < $350 \mathrm{~Pa}$ ) for a N95 FFR.

\section{On the Additivity of Composite Filters Made of Multiple Layers of Basic Filtration Media}

It is typically assumed that the penetration of composite filters, which is made of multiple layers of basic filtration media, is equivalent to the product of the penetration efficiency of the individual filtration media layers functioning independently. The particle collection efficiency of the composite filter samples can be calculated by Eq. (3):

$\eta_{n}=1-\left(1-\eta_{s}\right)^{n}$

where $\mathrm{n}$ is the number of basic media layers in a composite filter and $\eta_{\mathrm{s}}$ is the collection efficiency of a single layer of basic filtration media. In this part of the study, this assumption and equation are examined in the context of the tested composite filter samples.

Fig. 6 shows the comparison between the collection efficiency calculated by Eq. (3) and the measured collection efficiency for the composite filter samples made of multiple layers of basic media $\mathrm{C}$ and $\mathrm{F}$. The discrepancy between the measured and calculated collection efficiencies was found for the composite samples in the test particle size range. For our test composite filter samples, the measured efficiencies were less than the calculated ones in the test particle size range. Three possible reasons for the above observed discrepancy:
(1) the micro-structure uniformity of basic filtration media, leading to an issue of any given layer not necessarily being representative of the others in the calculation for overall collection efficiency; and (2) the loose layering of multiple basic filtration media, resulting in a different interfacial microstructure between any two adjacent layers (compared to that of basic media layers); (3) the change of charge status of test particles, resulting in different collection efficiencies for different basic media layers. A supplementary experiment was thus performed to test the potential explanations.

The composite filter sample with three layers of basic furnace media $\mathrm{F}$ was selected for this supplementary experiment. The particle penetration of three basic filter media and the composite filter were individually measured under the same face velocity of $10.5 \mathrm{~cm} \mathrm{~s}^{-1}$ and using DMAclassified particles of 50, 100 and $200 \mathrm{~nm}$ in sizes. The product of the measured penetration data of the three basic furnace filter media (i.e., $\mathrm{P}=\mathrm{P}_{1} \times \mathrm{P}_{2} \times \mathrm{P}_{3}$, where $\mathrm{P}_{\mathrm{i}}$ is the particle penetration of the basic media, $\mathrm{i}$ ) was compared to the measured penetration of the composite sample. Three composite filter samples were tested to calculate the average particle penetration efficiency for a specific size. Fig. 7 shows the comparison between the calculated and measured collection efficiencies obtained in this experiment. It was found that the measured particle collection efficiencies of the three-layered composite filter samples were again lower than the calculated, especially when using small particle sizes. The result above is consistent with the trend observed in Fig. 6. It was thus concluded that the discrepancy shown in Fig. 6 was not primarily due to the uniformity of the media microstructure. The observed discrepancy in the particle collection should be attributed to either the loose assembly of the multiple layers of basic filtration media or the charge status change of challenging particles. Further investigation will be required to identify the reason(s).

\section{CONCLUSIONS}

The size-dependent collection efficiency of four face 


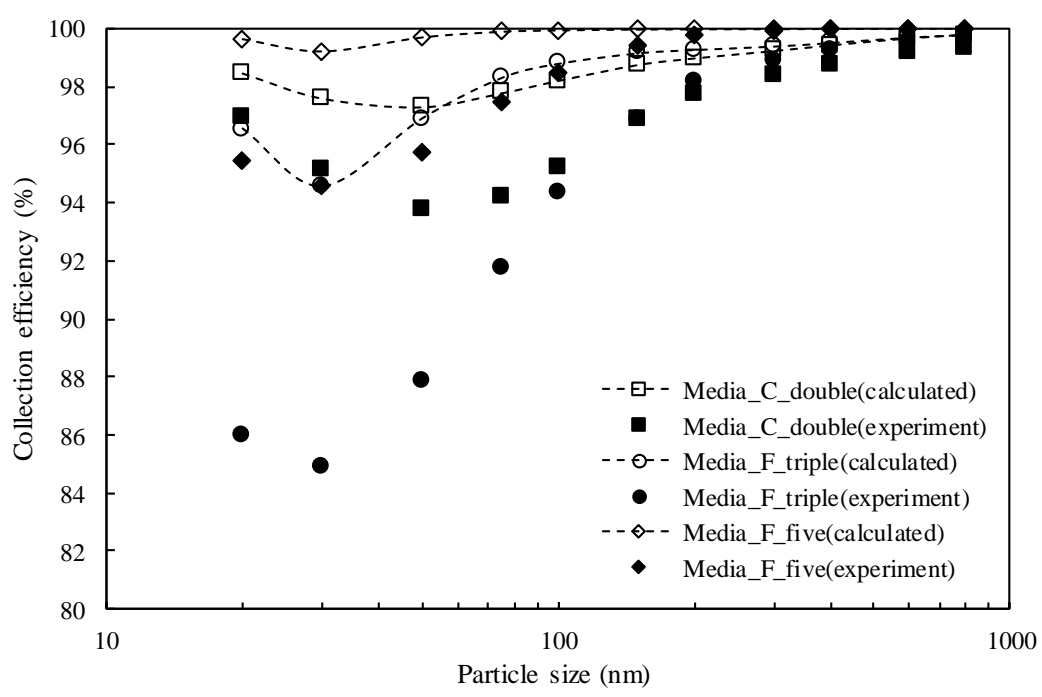

Fig. 6. Comparison of the measured and calculated collection efficiency of composite filter samples with multiple layers of basic media $\mathrm{C}$ and $\mathrm{F}$ at the face velocity of $10.5 \mathrm{~cm} \mathrm{~s}^{-1}$. Note that this calculation was based on the particle collection efficiency of a basic media (randomly selected).

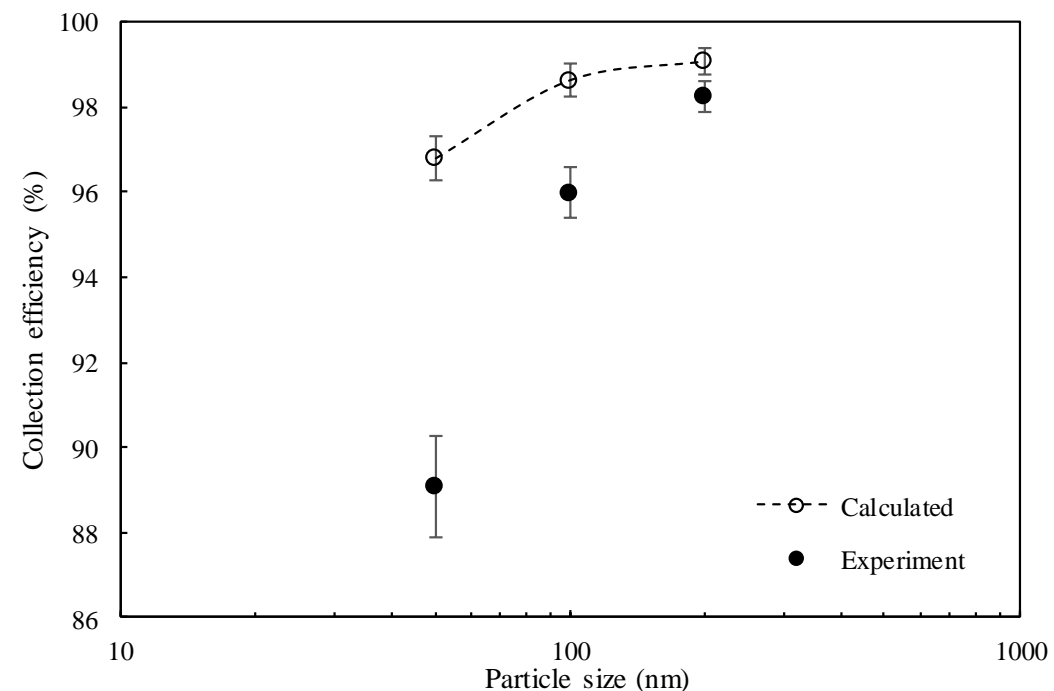

Fig. 7. Comparison of the measured and calculated collection efficiency of composite filter samples having triple layers of basic media $\mathrm{F}$ at the particle sizes of 50,100 and $200 \mathrm{~nm}$ (measured at the face velocity of $10.5 \mathrm{~cm} \mathrm{~s}^{-1}$ ). Note that this calculation was based on the measured particle collection efficiency of individual basic media layers used to construct the composite filters.

masks and one N95 FFR were measured under the same testing protocol. Test filter media samples were challenged with neutralized DMA-classified $\mathrm{NaCl}$ particles between the sizes of $20-800 \mathrm{~nm}$ and at a face velocity of $10.5 \mathrm{~cm} \mathrm{~s}^{-1}$. Two CPCs were used to measure the number concentration of particles upstream and downstream of the filter holder in which a test filter sample resided. The particle penetration of a test filter sample was calculated by taking the ratio of the downstream to the upstream particle concentrations. The pressure drop across the filter sample was also measured for the FOM (Figure of Merit) calculation. As expected, the minimum particle collection efficiency of the N95 FFR sample was higher than $95 \%$ and the minimum collection efficiency of all the face mask samples varied from $71.8 \%$ to $83.6 \%$. The MPPS for the N95 FFR and face masks were all $\sim 50 \mathrm{~nm}$ in this study. The N95 respirator had a higher FOM value than the face masks.

The strategy of using multiple layers of basic filtration media to construct a composite filter with a particle collection efficiency comparable to that of N95 FFRs (as an alternative media for $\mathrm{N} 95$ respirators) has been investigated. The basic filtration media selected in this study were face mask media and MERV13 furnace filter media (because they are readily available on the market). Our data shows that composite filters made of double/triple layers of face mask media can provide a comparable collection efficiency to a N95 FFR, especially for particles larger than $100 \mathrm{~nm}$. Although the collection efficiency of the composite filter 
with three layers of furnace filter media was less than that of the N95 respirator sample for particles less than $100 \mathrm{~nm}$ in size, the three-layered composite filter was able to provide a comparable collection efficiency for particles larger than $100 \mathrm{~nm}$ in diameter. The composite filter with five layers of furnace filter media could provide a collection efficiency like that of N95 respirator media in the test particle size range. Moreover, the composite samples of multi-layered face mask media had the lowest FOM, while the sample of multi-layered furnace media offered the highest FOM. The use of composite filters composed of multiple layers of basic furnace filter media is therefore the preferred option as an alternative media for a N95 respirator, given the current N95 respirator shortage.

The additivity of the particle collection efficiency for composite filters assembled from multiple layers was also examined. The discrepancy between the measured and calculated collection efficiencies of multi-layered composite samples (when loosely layered) was found. An additional experiment showed that the observed discrepancy was either due to the possible differences in the interfacial microstructure in a composite filter or the charge status change of the challenging particles during the particle collection, not the uniformity of basic filter media.

\section{ACKNOWLEDGEMENTS}

The authors thank the partial financial support of the members in the Center for Filtration Research, University of Minnesota: 3M Corporation, A.O. Smith Company, Applied Materials, Inc., BASF Corporation, Boeing Company, Corning Co., China Yancheng Environmental Protection Science and Technology City, Cummins Filtration Inc., Donaldson Company, Inc., Entegris, Inc., Ford Motor Company, Guangxi Wat Yuan Filtration System Co., Ltd, MSP Corporation; Samsung Electronics Co., Ltd., Xinxiang Shengda Filtration Technology Co.,Ltd., TSI Inc., W. L. Gore \& Associates, Inc., Shigematsu Works Co., Ltd., and the affiliate member National Institute for Occupational Safety and Health (NIOSH). Dr. Liu also thank the financial support by the China Scholarship Council (No. 201906445004).

\section{SUPPLEMENTARY MATERIAL}

Supplementary data associated with this article can be found in the online version at https://doi.org/10.4209/aaqr.2 020.07.0368

\section{REFERENCES}

Balazy, A., Toivola, M., Adhikari, A., Sivasubramani, S.K., Reponen, T. and Grinshpun, S.A. (2006a). Do N95 respirators provide $95 \%$ protection level against airborne viruses, and how adequate are surgical masks? Am. J. Infect. Control 34: 51-57. https://doi.org/10.1016/j.ajic.2 005.08.018

Balazy, A., Toivola, M., Reponen, T., Podgorski, A., Zimmer, A. and Grinshpun, S.A. (2006b). Manikin-based performance evaluation of N95 filtering-facepiece respirators challenged with nanoparticles. Ann. Occup. Hyg. 50: 259-269. https://doi.org/10.1093/annhyg/mei058 Brosseau, L.M., McCullough, N.V. and Vesley, D. (1997). Mycobacterial aerosol collection efficiency of respirator and surgical mask filters under varying conditions of flow and relative humidity. Appl. Occup. Environ. Hyg. 12: 435445. https://doi.org/10.1080/1047322X.1997.10389533

Cho, K.J., Jones, S., Jones, G., McKay, R., Grinshpun, S.A., Dwivedi, A., Shukla, R., Singh, U. and Reponen, T. (2010). Effect of particle size on respiratory protection provided by two types of N95 respirators used in agricultural settings. J. Occup. Environ. Hyg. 7: 622-627. https://doi.org/10.1080/15459624.2010.513910

Cowling, B., Zhou, Y., Ip, D., Leung, G. and Aiello, A. (2010). Face masks to prevent transmission of influenza virus: A systematic review. Epidemiol. Infect. 138: 449456. https://doi.org/10.1017/s0950268809991658

Davidson, C.S., Green, C.F., Gibbs, S.G., Schmid, K.K., Panlilio, A.L., Jensen, P.A. and Scarpino, P.V. (2013). Performance evaluation of selected N95 respirators and surgical masks when challenged with aerosolized endospores and inert particles. J. Occup. Environ. Hyg. 10: 461-467. https://doi.org/10.1080/15459624.2013.818 243

Eninger, R.M., Honda, T., Adhikari, A., Heinonen-Tanski, H., Reponen, T. and Grinshpun, S.A. (2008). Filter performance of N99 and N95 facepiece respirators against viruses and ultrafine particles. Ann. Occup. Hyg. 52: 385-396. https://doi.org/10.1093/annhyg/men019

Eshbaugh, J.P., Gardner, P.D., Richardson, A.W. and Hofacre, K.C. (2009). N95 and p100 respirator filter efficiency under high constant and cyclic flow. J. Occup. Environ. Hyg. 6: 52-61. https://doi.org/10.1080/1545962 0802558196

Gralton, J., Tovey, E., McLaws, M.L. and Rawlinson, W.D. (2011). The role of particle size in aerosolised pathogen transmission: A review. J. Infect. 62: 1-13. https://doi.org/10.1016/j.jinf.2010.11.010

He, X., Reponen, T., McKay, R.T. and Grinshpun, S.A. (2013). Effect of particle size on the performance of an N95 filtering facepiece respirator and a surgical mask at various breathing conditions. Aerosol Sci. Technol. 47: 1180-1187. https://doi.org/10.1080/02786826.2013.829209

Huang, S.H., Chen, C.W., Kuo, Y.M., Lai, C.Y., McKay, R. and Chen, C.C. (2013). Factors affecting filter penetration and quality factor of particulate respirators. Aerosol Air Qual. Res. 13: 162-171. https://doi.org/10.4209/aaqr.201 2.07.0179

Kutter, J.S., Spronken, M.I., Fraaij, P.L., Fouchier, R.A. and Herfst, S. (2018). Transmission routes of respiratory viruses among humans. Curr. Opin. Virol. 28: 142-151. https://doi.org/10.1016/j.coviro.2018.01.001

Lee, S.A., Grinshpun, S.A. and Reponen, T. (2008). Respiratory performance offered by N95 respirators and surgical masks: human subject evaluation with $\mathrm{NaCl}$ aerosol representing bacterial and viral particle size range. Ann. Occup. Hyg. 52: 177-185. https://doi.org/10.1093/a nnhyg/men005

Liu, Y., Gayle, A.A., Wilder-Smith, A. and Rocklöv, J. 
(2020). The reproductive number of COVID-19 is higher compared to SARS coronavirus. J. Travel Med. 27: taaa021. https://doi.org/10.1093/jtm/taaa021

MacIntyre, C.R., Cauchemez, S., Dwyer, D.E., Seale, H., Cheung, P., Browne, G., Fasher, M., Wood, J., Gao, Z. and Booy, R. (2009). Face mask use and control of respiratory virus transmission in households. Emerg. Infect. Dis. 15: 233-241. https://doi.org/10.3201/eid1502.081167

Oberg, T. and Brosseau, L.M. (2008). Surgical mask filter and fit performance. Am. J. Infect. Control 36: 276-282. https://doi.org/10.1016/j.ajic.2007.07.008

Prompetchara, E., Ketloy, C. and Palaga, T. (2020). Immune responses in COVID-19 and potential vaccines: Lessons learned from SARS and MERS epidemic. Asian Pac. J. Allergy Immunol. 38: 1-9. https://doi.org/10.12932/ap200220-0772

Rengasamy, S., King, W.P., Eimer, B.C. and Shaffer, R.E. (2008). Filtration performance of NIOSH-approved N95 and P100 filtering facepiece respirators against 4 to 30 nanometer-size nanoparticles. J. Occup. Environ. Hyg. 5: 556-564. https://doi.org/10.1080/15459620802275387

Rengasamy, S., Eimer, B.C. and Shaffer, R.E. (2009). Comparison of nanoparticle filtration performance of $\mathrm{NIOSH}$-approved and CE-marked particulate filtering facepiece respirators. Ann. Occup. Hyg. 53: 117-128. https://doi.org/10.1093/annhyg/men086

Rengasamy, S., Miller, A. and Eimer, B.C. (2011). Evaluation of the filtration performance of NIOSH-approved N95 filtering facepiece respirators by photometric and numberbased test methods. J. Occup. Environ. Hyg. 8: 23-30. https://doi.org/10.1080/15459624.2010.515556

Romay, F.J., Liu, B.Y. and Chae, S.J. (1998). Experimental study of electrostatic capture mechanisms in commercial electret filters. Aerosol Sci. Technol. 28: 224-234. https://doi.org/10.1080/02786829808965523

Stelzer-Braid, S., Oliver, B.G., Blazey, A.J., Argent, E., Newsome, T.P., Rawlinson, W.D. and Tovey, E.R. (2009). Exhalation of respiratory viruses by breathing, coughing, and talking. J. Med. Virol. 81: 1674-1679. https://doi.org/10.1002/jmv.21556

Wilder-Smith, A., Chiew, C.J. and Lee, V.J. (2020). Can we contain the COVID-19 outbreak with the same measures as for SARS? Lancet Infect. Dis. 20: E102-E107. https://doi.org/10.1016/S1473-3099(20)30129-8

Willeke, K., Qian, Y., Donnelly, J., Grinshpun, S. and Ulevicius, V. (1996). Penetration of airborne microorganisms through a surgical mask and a dust/mist respirator. Am. Ind. Hyg. Assoc. J. 57: 348-355. https://doi.org/10.1080/15428119691014882

World Health Organization (WHO) (2014). Infection prevention and control of epidemic-and pandemic prone acute respiratory infections in health care. World Health Organization.

Xie, X., Li, Y., Chwang, A., Ho, P. and Seto, W. (2007). How far droplets can move in indoor environments-revisiting the Wells evaporation-falling curve. Indoor Air 17: 211-225. https://doi.org/10.1111/j.1600-0668.2007.0 0469.x

Yang, S., Lee, G.W., Chen, C.M., Wu, C.C. and Yu, K.P. (2007). The size and concentration of droplets generated by coughing in human subjects. J. Aerosol Med. 20: 484494. https://doi.org/10.1089/jam.2007.0610

Zhu, N., Zhang, D., Wang, W., Li, X., Yang, B., Song, J., Zhao, X., Huang, B., Shi, W. and Lu, R. (2020). A novel coronavirus from patients with pneumonia in China, 2019. N. Engl. J. Med. 382: 727-733. https://doi.org/10.1 056/NEJMoa2001017

Zuo, Z., Kuehn, T.H. and Pui, D.Y. (2013). Performance evaluation of filtering facepiece respirators using virus aerosols. Am. J. Infect. Control 41: 80-82. https://doi.org/ 10.1016/j.ajic.2012.01.010

Received for review, July 2, 2020 Revised, September 9, 2020 Accepted, September 11, 2020 